\title{
Expression of BAG-1 is closely related to cell differentiation and TNM stage in esophageal cancer and its downregulation inhibits the proliferation and invasion of human esophageal carcinoma cells
}

\author{
BO HUANG, HONGLI ZHOU, XIANPING LANG, ZHILIANG LIU, \\ FEI XIONG and SIWANG WANG

\begin{abstract}
Department of Thoracic Surgery, The First Affiliated Hospital of Liaoning Medical University,
\end{abstract} \\ Jinzhou, Liaoning 121000, P.R. China
}

Received April 2, 2014; Accepted June 13, 2014

DOI: $10.3892 /$ or.2014.3356

\begin{abstract}
The aim of the present study was to explore the correlation of BAG-1 with clinical characteristics of esophageal cancer and its effects on the proliferation, invasion and apoptosis of the esophageal carcinoma cell line Eca109. Therefore, the expression of BAG-1 was assessed in esophageal carcinoma tumor tissues and adjacent normal esophageal tissues. The siRNA vector of BAG-1 was constructed and transfected into the Eca109 cell line, and then fluorescence microscopy was used to evaluate the transfection efficiency. MTT and Transwell assays were used to study cell proliferation and invasive activity, and the apoptosis rate was assessed by flow cytometry. Western blotting was adopted to assess the silencing efficiency and expression of related gene bcl-2. The results revealed that BAG-1 expression was low in the adjacent normal esophageal tissues while expression was high in the esophageal carcinoma tissues. After Eca109 cells were transfected with BAG-1-siRNA, the proliferation and invasive capabilities of the cells were significantly decreased while the apoptosis rate was greatly enhanced $(\mathrm{P}<0.01)$. When the expression of BAG-1 in the Eca109 cells was downregulated, the expression of bcl-2 was significantly abated $(\mathrm{P}<0.05)$. In conclusion, BAG-1 is closely connected with the pathogenesis and development of esophageal carcinoma, which may act through affecting bcl-2.
\end{abstract}

\section{Introduction}

BAG-1 is an anti-apoptotic protein that binds to bcl-2. It is a multi-functional protein that interacts with many other cellular

Correspondence to: Dr Hongli Zhou, Department of Nephrology, The First Affiliated Hospital of Liaoning Medical University, 2 People Street, Jinzhou, Liaoning, 121000, P.R. China

E-mail: zhouhongli77@126.com

Key words: BAG-1, esophageal carcinoma, siRNA proteins (1-4). Apoptosis-related factors are candidates for cancer therapy. Downregulation of the expression of bcl-2 by ribozymes or antisense oligonucleotides was found to result in apoptosis $(5,6)$. BAG-1 was reported to be a partner of bcl-2 collaborating in the suppression of cell death (7). To date, BAG-1 expression has been implicated in breast, lung, laryngeal and oral cavity cancers (8-11).

Esophageal carcinoma is a malignant digestive tract tumor and is associated with a poor prognosis. The pathogenesis and development of esophageal carcinoma are complicated processes, and in most cases, esophageal carcinoma exhibits no symptoms until the cancer is at an advanced stage. The overall survival rate still remains low, and less than $20 \%$ of patients survive for more than five years (12). To date, the pathological progression of esophageal cancer has been thoroughly described, while the molecular mechanisms are less well understood (13).

Few studies have investigated the role of BAG-1 in the pathogenesis and development of esophageal carcinoma (14). Therefore, in this study, we initially studied the expression of BAG-1 in esophageal carcinoma and adjacent normal tissues. RNA interference (RNAi) provides a new approach with which to study gene functions $(15,16)$. Using this method we downregulated BAG-1 expression in esophageal cancer cells to investigate the function of BAG-1. We constructed the siRNA vector of BAG-1, transfected it into the Eca109 cell line to downregulate the expression of BAG-1, and investigated its role in cell proliferation, invasion and the apoptosis of esophageal carcinoma.

\section{Materials and methods}

The present study was approved and registered by the Ethics Committee of the First Affiliated Hospital of Liaoning Medical University in January, 2010. The related screening and analysis of the resected samples were approved by the Ethics Committee of Liaoning Medical University, and written consent forms for the use of these samples were signed and participation in the study was agreed upon by all subjects. 
Sample collection. A total of 92 esophageal carcinoma and 15 adjacent normal tissue samples (at least $5 \mathrm{~cm}$ away from the edge of the cancer tissue) were collected from the sample preservation center of our hospital. These esophageal carcinoma (and adjacent normal tissue) samples were all resected at the Department of Thoracic Surgery from January 2010 to December 2012. The inclusion criteria of these sample were: i) patients had not received any prior radiotherapy and chemotherapy treatment; ii) each patient had received a medical examination including cranial CT scan, chest CT scan, abdominal CT scan and ECT, which could define the TNM stage of the patient clearly; iii) patients had received radical surgery with sufficient tissue samples prepared in paraffin blocks for further testing; iv) patients who had at least 2 concurrent primary tumors were excluded. All samples were fixed in $10 \%$ formaldehyde and paraffin-embedded. The samples were routinely and serially sectioned with a thickness of $5 \mu \mathrm{m}$, and then were immunohistochemically stained. The esophageal carcinomas were staged according to the tumornode-metastasis (TNM) staging system stipulated by the 7 th edition of the American Joint Committee on Cancer (AJCC) Cancer Staging Manual (2009).

Immunohistochemistry. Sections were deparaffinized and hydrated stepwise in xylene and graded ethanol, washed with phosphate-buffered saline (PBS), and recovered through microwave irradiation. $\mathrm{H}_{2} \mathrm{O}_{2}$ solution $(3 \%)$ was added and cultured for $10 \mathrm{~min}$, and then washed with PBS. Goat blocking serum was supplied and cultured at room temperature, and the diluted primary antibody (1:100; rabbit anti-human BAG-1 polyclonal antibody; Santa Cruz) was applied. Sections, after remaining overnight at $4^{\circ} \mathrm{C}$, received PBS washing, and then the secondary antibody (1:500; goat anti-rabbit antibody; Santa Cruz) was added and cultured at $37^{\circ} \mathrm{C}$ for $20 \mathrm{~min}$. Newly prepared DAB chromogenic reagent was applied and cultured at $37^{\circ} \mathrm{C}$ for 5-10 min. Nuclei were then stained with hematoxylin and eosin (H\&E). The staining proportion was classified as $-(\leq 10 \%),+(11-50 \%)$ and $++(>50 \%)$.

Expression of BAG-1 protein in tissue samples. Western blotting was used to determine the protein level in the cancer tissues. Briefly, frozen tissues were homogenized with lysis buffer, and then centrifuged at $4^{\circ} \mathrm{C}$ for $30 \mathrm{~min}(12,000 \mathrm{rpm})$. The supernatant was collected and the BCA method was used to determine protein concentration. A $10 \%$ polyacrylamide gel was prepared to load the protein samples, and 5\% nonfat dry milk was added to block the non-specific antigen. The primary antibody (1:250; rabbit anti-human BAG-1 polyclonal antibody) and secondary antibody (1:500; goat anti-rabbit antibody) were applied. Each sample was also probed with $\beta$-actin antibody (Sigma-Aldrich) as a loading control.

Cell lines. Esophageal carcinoma cell line Eca109 was purchased from Shanghai Biological Sciences Institute (China). It was cultured in RPMI-1640 medium, supplemented with $10 \% \mathrm{FBS}, 100 \mathrm{U} / \mathrm{ml}$ penicillin and $100 \mu \mathrm{g} / \mathrm{ml}$ streptomycin and maintained in a $5 \% \mathrm{CO}_{2}$ humidified atmosphere at $37^{\circ} \mathrm{C}$.

Vector construction and transfection. Small interfering RNAs (siRNAs) targeting BAG-1 were chemically synthesized by Takara Biotechnology Co. Ltd. (Dalian, China). The three siRNA sequences were: (si-1) forward, 5'-GATCCGTCGAG CAATGAGAGGTATGACCTTCATCGATGAAGGTCATAC CTCTCATTGCCTTTTTTG-3' and reverse, 5'-AATTCAAAA AAGGCAATGAGAGGTATGACCTTCATCGATGAAGGT CATACCTCTCATTGCCTAGCG-3'; (si-2) forward, 5'-GAT CCGTCGATGGTCGTCACCCACAGCAATATCGATATTG CTGTGGGTGACGACCACTTTTTTG3' and reverse, 5'-AAT TCAAAAAAGTGGTCATCACCCACAGCAATATCGATA TGCTGTGGGTGACGACCACTAGCG-3'. The negative siRNA sequence was: (si-N) forward, 5'GATCCGCGAGAC CTCAGTATGTTACCTGTGAAGCCACAGATGGGGTAA CATACTGAGGTTCGCTTTTTTG 3' (control group). The DNA sequence was fully ligated into the pRNAT-U6.1/ Neo-siRNA vector (Takara Biotechnology, Dalian, China) at $4^{\circ} \mathrm{C}$ overnight using the Takara DNA Ligation kit. There were two targeted recombinant plasmids (BAG-1-siRNA-1, BAG-1siRNA-2), one negative control (BAG-1-siRNA-N), and the untreated cells served as the blank control. Eca109 cells were seeded $\left(2 \times 10^{5}\right.$ cells/well) in a 6 -well plate. After $24 \mathrm{~h}$ of incubation, the cells were transfected with BAG-1-siRNA-1, BAG-1-siRNA-2 or BAG-1-siRNA-N in serum-free medium using Lipofectamine 2000 (Invitrogen, Carlsbad, CA, USA). Vectors $(5 \mu \mathrm{g})$ and $10 \mu \mathrm{l}$ of Lipofectamine 2000 were mixed and incubated for $15 \mathrm{~min}$ at room temperature. The mixture was then added to the Eca109 cells (no serum and antibiotics), and after incubation for $6 \mathrm{~h}$, the mixture was replaced by full medium (including serum but no antibiotics).

MTT assay. Twenty-four hours after transfection, cells from the 4 groups were loaded in a 96 -well plate at $2 \times 10^{3}$ cells/well, cultured with the RPMI-1640 medium with $10 \% \mathrm{FBS}$, at time points of 24,48 and $72 \mathrm{~h}$. The medium was removed from each well, and $20 \mu \mathrm{l}$ of 3-(4,5-dimethylthiazol-2-yl)2,5-diphenyltetrazolium bromide (MTT; $5 \mathrm{mg} / \mathrm{ml}$ in PBS) was added in the absence of light, and the formazan crystals were produced over a 4-h incubation period. Then the supernatant was removed, and $150 \mu \mathrm{l}$ of DMSO was added into each well. The dark-blue crystals of MTT were dissolved by shaking the plates at room temperature for $10 \mathrm{~min}$, and the absorbance was then measured on a Bio-Rad microplate reader (Bio-Rad, Hercules, CA, USA) using a test wavelength of $490 \mathrm{~nm}$ and a reference wavelength of $570 \mathrm{~nm}$.

Transwell assay. The invasiveness of Eca109 cells was assayed using modified Transwell chambers. Polycarbonate filter (pore size, $8 \mu \mathrm{m}$ ) separating the upper and lower compartments was coated with $50 \mu \mathrm{g}$ of reconstituted basement membrane (Matrigel; BD, Bedford, MA, USA). Thirty-six hours after transfection, the full medium was replaced with serum-free culture medium. Eight hours later, they were digested to a suspension at a density of $1 \times 10^{4} / \mathrm{ml}$. Cells were seeded into the Transwell chamber. The chamber was placed into a 24-well culture plate with $500 \mu \mathrm{l}$ of RPMI-1640 medium containing $15 \%$ serum added outside of the chamber, and $200 \mu \mathrm{l}$ cell suspension was added to the chamber. After $48 \mathrm{~h}$ of incubation at $37^{\circ} \mathrm{C}$, cells on the upper surface of the filter that had not invaded through the Matrigel were removed completely with cotton swabs. Cells that had invaded remained on the filter. Cells on the polycarbonate filter were fixed with H\&E. The 


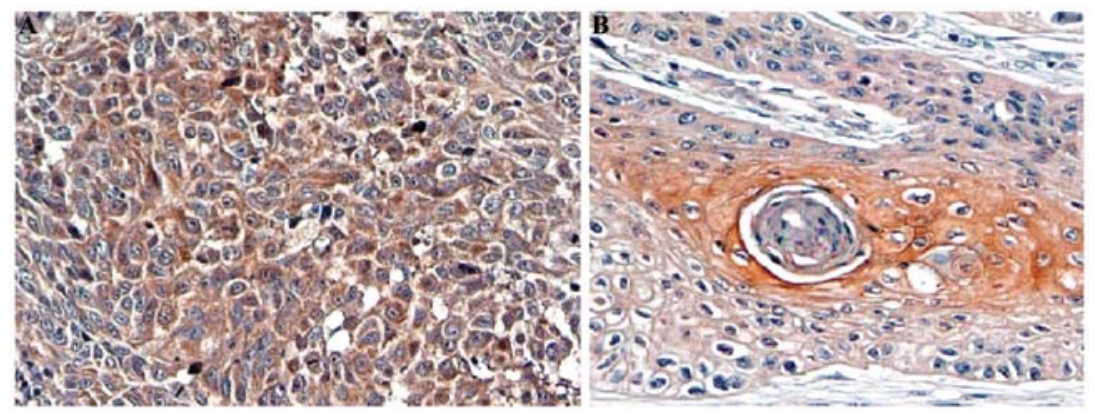

Figure 1. Immunohistochemistry of BAG-1 in esophageal carcinoma tissues: (A) poorly differentiated tissue, (B) well differentiated tissue.

Table I. The relationship between the positive expression of BAG-1 protein in esophageal squamous cell carcinoma and the patient characteristics.

\begin{tabular}{lrrrrrr}
\hline & & \multicolumn{2}{c}{ BAG-1 protein } & & \\
\cline { 3 - 5 } & $\mathrm{n}(92)$ & - & + & ++ & $\chi^{2}$ & P-value \\
\hline Gender & & & & & 0.473 & 0.491 \\
$\quad$ Male & 67 & 21 & 13 & 33 & & \\
Female & 25 & 6 & 8 & 11 & & \\
Age (years) & & & & & 0.915 & 0.339 \\
$\quad$ 60 & 44 & 15 & 12 & 17 & & \\
$>60$ & 48 & 12 & 9 & 27 & & \\
Location & & & & & 0.070 & 0.791 \\
$\quad$ Mid-thoracic & 56 & 17 & 14 & 25 & & \\
Lower-thoracic & 36 & 10 & 7 & 19 & & \\
Degree of & & & & & & \\
differentiation & & & & & 15.713 & $<0.001$ \\
$\quad$ Well & 39 & 20 & 8 & 11 & & \\
$\quad$ Moderate & 37 & 5 & 10 & 22 & & \\
$\quad$ Poorly & 16 & 2 & 3 & 11 & & \\
$\quad$ TNM stage & & & & & 5.904 & 0.015 \\
I+II & 40 & 17 & 13 & 10 & & \\
$\quad$ III & 52 & 10 & 9 & 33 & & \\
\hline
\end{tabular}

number of invasive cells was counted under a microscope (magnification, x200).

Flow cytometry. Thirty-six hours after transfection, the cells were washed with PBS twice, then digested and centrifuged. Then apoptosis detection was carried out according to the instructions of the detection kit (PE Annexin V Apoptosis I). Cells were resuspended in $1 \mathrm{X}$ binding buffer $\left(1 \times 10^{6} / \mathrm{ml}\right)$. A total of $100 \mu \mathrm{l}$ was drawn and $5 \mu \mathrm{l}$ of PE Annexin $\mathrm{V}$ and $5 \mu \mathrm{l}$ of $7-A A D$ were added. Cells were cultured in a rotary system at room temperature for $15 \mathrm{~min}$, and $400 \mu \mathrm{l}$ of $1 \mathrm{X}$ binding buffer was added, and analysis was performed within $1 \mathrm{~h}$.

Western blotting of BAG-1 and bcl-2. Cells were washed three times with ice-cold PBS, then centrifuged at $4^{\circ} \mathrm{C}$ for $30 \mathrm{~min}$ $(12,000 \mathrm{rpm})$. The supernatant was collected and the BCA

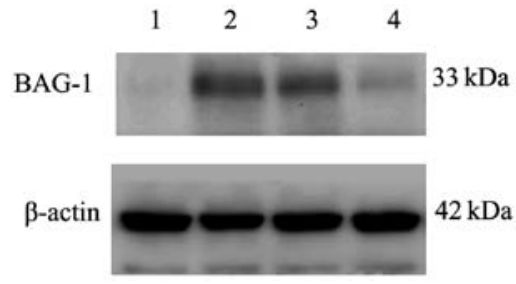

Figure 2. Expression of BAG-1 protein in esophageal carcinoma and its adjacent normal tissues. Lanes 1 and 4, adjacent non-tumor tissue, and lanes 2 and 3, esophageal carcinoma tissue.

method was used to determine the protein concentration. A $10 \%$ polyacrylamide gel was prepared to load protein samples, and 5\% nonfat dry milk was added to block the non-specific antigen. The primary antibody (1:250; rabbit anti-human BAG-1 or bcl-2 polyclonal antibody) and the secondary antibody (1:500; goat anti-rabbit antibody) were applied. Each sample was also probed with $\beta$-actin antibody as a loading control.

Statistical analysis. The images were analyzed by Quantity One software. All laboratory data are represented as mean \pm standard deviation (SD). The $\chi^{2}$ test and single factor analysis of variance (ANOVA) were performed with SPSS 17.0 software, and $\mathrm{P}<0.05$ was considered to indicate a statistically significant difference.

\section{Results}

A total of 92 samples were successfully selected, among which 67 were resected from males and 25 from females. The average patient age was 59 years (range 35-76). Of the total samples, 39 cases were well differentiated, 37 cases were moderately differentiated, and 16 cases were poorly differentiated. Forty cases were classified as stage I and stage II, and 52 cases were stage III (Table I).

BAG-1 expression is low in adjacent normal tissues while high in esophageal carcinoma tissues. Immunohistochemistry showed that the BAG-1 protein was mainly expressed in the cytoplasm and the nuclei and exhibited yellow or brown-color staining. Its expression was significantly higher in the poorly differentiated cells when compared with the well differentiated cells (Fig. 1). The expression of BAG-1 in the esophageal carcinoma tissues was not correlated with patient age, gender 

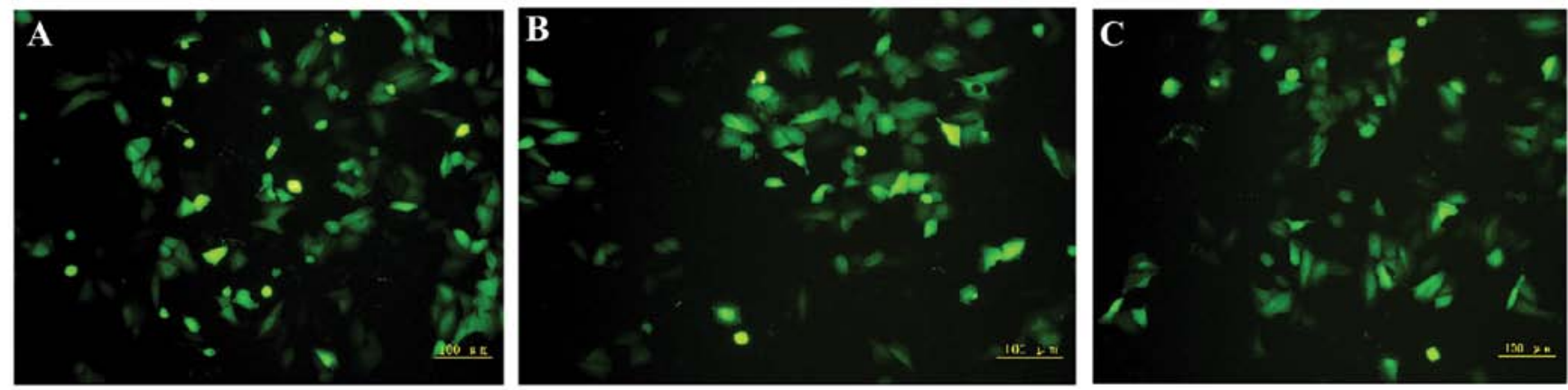

Figure 3. Expression of green fluorescent protein (GFP) in the ECA109 cells after transfection for 48 h. (A) BAG-1-SiRNA-1 group (magnification, x100); (B) BAG-1-SiRNA-2 group (magnification, x100); (C) BAG-1-SiRNA-N group (magnification, x100).

Table II. Relationship between the positive expression of BAG-1 protein in esophageal squamous tumor tissues and adjacent normal esophageal tissues.

\begin{tabular}{|c|c|c|c|c|c|c|}
\hline & \multirow[b]{2}{*}{$\mathrm{n}$} & \multicolumn{3}{|c|}{ BAG-1 } & \multirow[b]{2}{*}{$\chi^{2}$} & \multirow[b]{2}{*}{ P-value } \\
\hline & & - & + & ++ & & \\
\hline \multicolumn{7}{|l|}{ Tissue } \\
\hline Tumor & 92 & 27 & 21 & 44 & 14.285 & $<0.001$ \\
\hline Adjacent normal & 15 & 12 & 2 & 1 & & \\
\hline
\end{tabular}

and tumor location (Table I). Statistical difference was noted in BAG-1 protein levels among the esophageal carcinoma tissues with different degrees of differentiation $\left(\chi^{2}=15.733, \mathrm{P}<0.001\right)$, and the degree of differentiation was negatively correlated with the expression of BAG-1 (Fig. 1). A statistical difference was found in the expression of BAG-1 among the TNM stages in the esophageal carcinoma cases $\left(\chi^{2}=5.904 ; \mathrm{P}=0.015\right)$, and the expression was positively correlated with TNM stage. There were 70.7\% (65/92) of cases with positive expression of BAG-1 protein in the esophageal carcinoma tissues while the rate of positive expression was significantly low in the adjacent normal tissues $(20 \% ; 3 / 15 ; \mathrm{P}<0.001$; Table II). The western blotting results (Fig. 2) showed that BAG-1 was expressed weakly in the adjacent normal tissues of the esophageal carcinoma, while highly expressed in the esophageal carcinoma tissues.

Fluorescence microscopy. After the Eca109 cells were transfected with BAG-1-siRNA-1, BAG-1-siRNA-2 or BAG-1-siRNA-N, green fluorescence was observed in the cytoplasm. As shown in Fig. 3, under fluorescence microscopy, the transfection efficiency of the three groups (BAG-1-siRNA-1, BAG-1-siRNA-2 and BAG-1-siRNA-N) was satisfactory with all exceeding $70 \%$. We observed that some of the cells treated with BAG-1-siRNA were less confluent or became smaller and orbicular compared with the control. Consistently, there were fewer cells in both the BAG-1-siRNA-1 and BAG-1-siRNA-2 transfected cells as compared with the BAG-1-siRNA-N transfected and control cells cultured for $72 \mathrm{~h}$ after transfection. The BAG-1-siRNA treatment decreased the number of Eca109 cells implying that BAG-1 participates in cell cycle progression and cell survival.
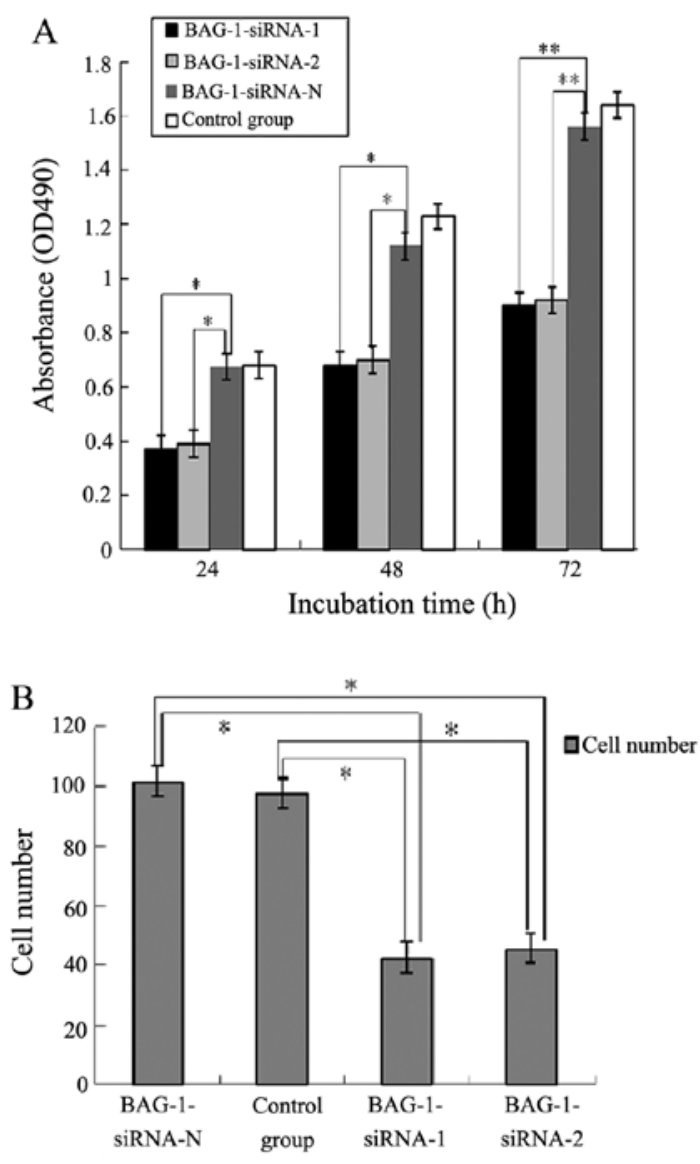

Results of invasion assays

Figure 4. Proliferation and migration ability decreased after transfection Proliferation tested by MTT assay. (A) Decrease in the proliferation potential of cells transfected with BAG-1-siRNA was noted. Esophageal cancer cells seeded in 96-well microplates were cultured for 24,48 and $72 \mathrm{~h}$, and the cell number was determined by absorbance as described in Materials and methods; ${ }^{*} \mathrm{P}<0.05,{ }^{* *} \mathrm{P}<0.01$, compared with BAG-1-siRNA-N (ANOVA). (B) Histogram of the transmembrane cell count comparison. A reduced number of BAG-1-siRNA-2 groups was noted when compared with the number of ECA109 cells or ECA109 cells transfected with BAG-1-siRNA-N. ${ }^{*} \mathrm{P}<0.05$, compared with ECA109 cells and BAG-1-siRNA-N (ANOVA). Data are representative of 1 of 5 of independent assays.

Decrease in proliferation and invasion after transfection. MTT assay showed that the proliferation of cells in the BAG-1siRNA-N and blank control groups increased almost 3 -fold from 24 to $72 \mathrm{~h}$ after transfection (Fig. 4A), while that in the 
A

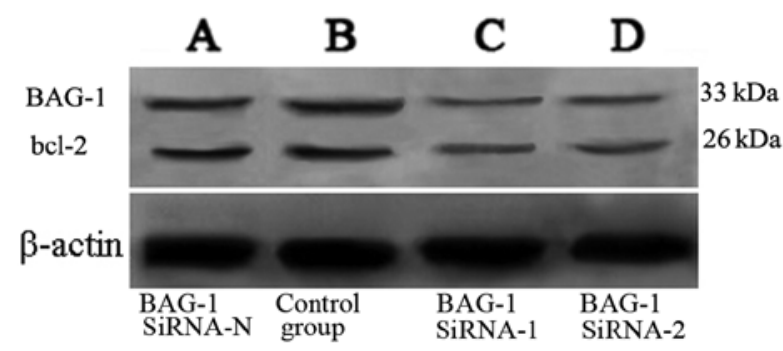

B

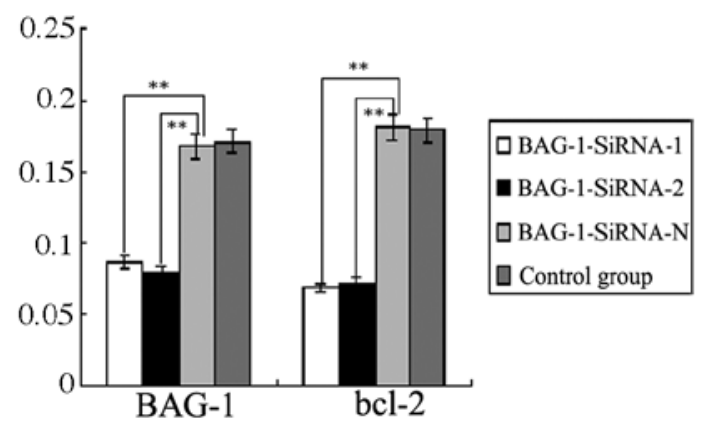

Figure 5. Expression levels of BAG-1 and bcl-2 are decreased after transfection. (A) Western blotting results. $\beta$-actin served as the control. (B) Quantitation of expression as displayed in a histogram. ${ }^{* *} \mathrm{P}<0.01$, compared with the blank control.

BAG-1-siRNA-1 and BAG-1-siRNA-2 groups was relatively slow, and doubled at $72 \mathrm{~h}$. Compared with the negative control, proliferation was significantly retarded $(\mathrm{P}<0.01)$.

To determine the possible role of BAG-1-siRNA in the invasive ability of esophageal cancer cells, we used a Transwell invasion assay. Eca109 cells and Eca109 cells transfected with BAG-1-siRNA-1, BAG-1-siRNA-2 and BAG-1-siRNA-N were placed for $48 \mathrm{~h}$ on Matrigel-coated filters, which were stained with $\mathrm{H} \& \mathrm{E}$ and inspected under a microscope. The cell numbers of invasive Eca109 cells transfected with BAG-1-siRNA-1 and BAG-1-siRNA-2 were significantly decreased when compared with the invasive cell numbers in the siRNA-N and control groups $(\mathrm{P}<0.05)$. There was no significant difference between the siRNA-N group and the control group ( $\mathrm{P}>0.05$; Fig. 4B). These data demonstrated that knockdown of BAG-1 by transient transfection of BAG-1-siRNA decreased the proliferation and inhibited the invasion of esophageal carcinoma cells in vitro.

Expression of BAG-1 and bcl-2 in the transfected Ecal09 cells. Compared with the BAG-1-siRNA-N group and the blank control group, western blotting results showed that the expression of BAG-1 protein was significantly decreased in the BAG-1-siRNA-1 and BAG-1-siRNA-2 groups compared with expression in the blank control $(\mathrm{P}<0.05$; Fig. 5), while BAG-1 protein expression in the BAG-1-siRNA-N group almost remained unchanged. Concomitantly, the expression of bcl-2 was significantly reduced in the BAG-1-siRNA-1 and BAG-1siRNA-2 groups compared with bcl-2 expression in the blank control ( $\mathrm{P}<0.05$; Fig. 5). Expression in the BAG-1-siRNA-N group was the same as that in the blank control.

Apoptosis rate is increased after transfection. Flow cytometric analysis showed that the apoptosis rate was significantly increased $(\mathrm{P}<0.01)$ in the BAG-1-siRNA-1 and BAG-1-siRNA-2 transfected cells compared with the negative control; there was no significant difference in the apoptotic rate between cells transfected with BAG-1-siRNA-N and the blank control $(\mathrm{P}>0.05)$ (Table III).

\section{Discussion}

Apoptosis is a cell death process that involves many genes, and the occurrence and development of tumors are the result of abnormal expression of oncogenes, tumor-suppressor
Table III. Analysis of the rate of apoptosis for each cell group.

\begin{tabular}{lc}
\hline Group & Apoptosis $(\%)$ \\
\hline BAG-1-siRNA-1 & $15.87 \pm 1.12^{\mathrm{a}}$ \\
BAG-1-siRNA-2 & $16.26 \pm 1.06^{\mathrm{a}}$ \\
BAG-1-siRNA-N & $4.64 \pm 0.72$ \\
Blank control & $5.14 \pm 0.48$
\end{tabular}

${ }^{\text {a }}<0.01$, compared with the BAG-1-siRNA-N group.

genes and apoptosis-related gene changes in cell proliferation and apoptosis. Apoptosis-related factors are candidates for cancer therapy. Downregulation of the expression of bcl-2 by ribozymes or antisense oligonucleotides results in apoptosis. BAG-1 was reported to be a partner of bcl-2 collaborating in the suppression of cell death. Overexpression of BAG-1 caused an acceleration in cell motility in human gastric and cervical cancer cells $(17,18)$. To date, few reports exist concerning the role of the BAG-1 gene in esophageal carcinoma (19). In the present study, we observed that BAG-1 was highly expressed in esophageal cancer tissues, when compared with that in adjacent normal tissues. Importantly, we observed that the expression of BAG-1 was closely related to cancer differentiation and TNM stage, which suggests that BAG-1 may contribute to invasion and metastasis of esophageal cancer.

The discovery of small interfering RNAs (siRNAs) may well be one of the transforming events in biology in the past decade. This technology has become a powerful tool in the studies of gene function, carcinoma and viral disease therapy $(20,21)$. Liu et al silenced the BAG-1 gene in lung cancer cell lines A549 and L9981, resulting in changes in expression of apoptosis-related genes and sensitization of A549 and L9981 cells to cisplatin-induced apoptosis (22). Enlightened by this research, we constructed a BAG-1 siRNA vector and transfected it into the Eca109 cell line to downregulate the expression of the BAG-1 gene. Our results showed that transfection of BAG-1-siRNA-1 or BAG-1-siRNA-2 into Eca109 cells, significantly inhibited cell proliferation and invasion. In addition, BAG-1-siRNA induced the apoptosis of Eca109 cells in vitro, which confirmed that BAG-1 plays a major role in controlling cell proliferation, invasion and apoptosis. Our results indicate that targeting BAG-1 could be a strategy for the development of esophageal tumor therapy. 
In our study, more than $70 \%$ of the plasmids in the BAG-1-siRNA-1, BAG-1-siRNA-2 and BAG-1-siRNA-N groups were transfected successfully, while the proliferation, migration and apoptosis rate in the BAG-1-siRNA-N group showed almost no difference with the control group. These results indicate that the safety and efficacy of the interfering vector system was reliable at the cellular level, and BAG-1 is an ideal target for esophageal carcinoma.

BAG-1 is an anti-apoptotic protein that binds to bcl-2. We confirmed that with a decrease in BAG-1, the bcl-2 level decreased in the esophageal cancer tissues. When the amount of bcl-2 decreased, the cell apoptosis rate significantly increased, and the cell proliferation and differentiation capabilities decreased. This may be one of the mechanisms of BAG-1 influence on esophageal cancer proliferation, invasion and apoptosis.

At present, a wide array of genes which could possibly affect the pathogenesis and development of esophageal carcinoma have been investigated, and targeted RNAi of CXCR4, MMP-2, XIAP, MTA1 and ABCE1 have been reported for esophageal carcinoma in vitro or in vivo with downregulation ranging from $20-80 \%$ (23-26). Yet, few studies have researched the role of the BAG-1 gene in esophageal carcinoma. Our study demonstrated that BAG-1 could be a future target for the treatment of esophageal carcinoma. In summary, our study showed that BAG-1 was highly expressed in esophageal cancer tissues, compared with that in adjacent normal tissues. The expression of BAG-1 was closely related to cancer cell differentiation and TNM stage. The transfection vector system we constructed significantly downregulated the BAG-1 level in esophageal cancer cells and it also inhibited cell proliferation, invasion, and induced cell apoptosis. Our findings may provide novel insights for the development of gene therapy technology with which to treat patients with esophageal cancer.

\section{Acknowledgements}

This research was supported by the National Natural Science Foundation of China (30973520) and the Science and Technology Department of Liaoning Province (series nos. 201202143 and 2013022038).

\section{References}

1. Yang L, McBurney D, Tang SC, Carlson SG and Horton WE Jr: A novel role for Bcl-2 associated-athanogene-1 (Bag-1) in regulation of the endoplasmic reticulum stress response in mammalian chondrocytes. J Cell Biochem 102: 786-800, 2007.

2. Takayama S, Krajewski S, Krajewska M, Kitada S, Zapata JM, Kochel K, Knee D, Scudiero D, Tudor G, Miller GJ, Miyashita T, Yamada M and Reed JC: Expression and location of Hsp70/Hsc-binding anti-apoptotic protein BAG-1 and its variants in normal tissues and tumor cell lines. Cancer Res 58: 3116-3131, 1998

3. Knapp RT, Steiner A, Schmidt U, Hafner K, Holsboer F and Rein T: BAG-1 diversely affects steroid receptor activity. Biochem J 441: 297-303, 2012.

4. Elliott E, Tsvetkov P and Ginzburg I: BAG-1 associates with Hsc70.Tau complex and regulates the proteasomal degradation of Tau protein. J Biol Chem 282: 37276-37284, 2007.

5. Kunze D, Kraemer K, Erdmann K, Froehner M, Wirth MP and Fuessel S: Simultaneous siRNA-mediated knockdown of antiapoptotic BCL-2, Bcl-xL, XIAP and survivin in bladder cancer cells. Int J Oncol 41: 1271-1277, 2012.
6. Xu HD, Wu D, Gu JH, Ge JB, Wu JC, Han R, Liang ZQ and Qin ZH: The pro-survival role of autophagy depends on Bcl-2 under nutrition stress conditions. PLoS One 8: e63232, 2013.

7. Roth W, Grimmel C, Rieger L, Strik H, Takayama S, Krajewski S, Meyermann R, Dichgans J, Reed JC and Weller M: Bag-1 and Bcl-2 gene transfer in malignant glioma: modulation of cell cycle regulation and apoptosis. Brain Pathol 10: 223-234, 2000.

8. Nadler Y, Camp RL, Giltnane JM, Moeder C, Rimm DL, Kluger HM and Kluger Y: Expression patterns and prognostic value of Bag-1 and Bcl-2 in breast cancer. Breast Cancer Res 10: R35, 2008.

9. Wang YD, Ha MW, Cheng J, Zhang WL, Cong X, Tong CY and Sun J: The role of expression and polymorphism of the BAG-1 gene in response to platinum-based chemotherapeutics in NSCLC. Oncol Rep 27: 979-986, 2012.

10. Yamauchi H, Adachi M, Sakata K, Hareyama M, Satoh M, Himi T, Takayama S, Reed JC and Imai K: Nuclear BAG-1 localization and the risk of recurrence after radiation therapy in laryngeal carcinomas. Cancer Lett 165: 103-110, 2001.

11. Coutinho-Camillo CM, Lourenço SV, Nishimoto IN, Kowalski LP and Soares FA: Expression of Bcl-2 family proteins and association with clinicopathological characteristics of oral squamous cell carcinoma. Histopathology 57: 304-316, 2010.

12. Jemal A, Siegel R, Ward E, Hao Y, Xu J, Murray T and Thun MJ: Cancer statistics, 2008. CA Cancer J Clin 58: 71-96, 2008.

13. Zhu L, Yan W, Rodriguez-Canales J, Rosenberg AM, Hu N, Goldstein AM, Taylor PR, Erickson HS, Emmert-Buck MR and Tangrea MA: MicroRNA analysis of microdissected normal squamous esophageal epithelium and tumor cells. Am J Cancer Res 1: 574-584, 2011.

14. Noguchi T, Takeno S, Shibata T, Fumoto S, Uchida Y, Yokoyama S, Gabbert HE and Müller W: Nuclear BAG-1 expression is a biomarker of poor prognosis in esophageal squamous cell carcinoma. Dis Esophagus 16: 107-111, 2003.

15. Huang B, Zhou H, Wang X and Liu Z: Silencing SATB1 with siRNA inhibits the proliferation and invasion of small cell lung cancer cells. Cancer Cell Int 13: 8, 2013.

16. Huang B, Gao Y, Tian D and Zheng M: A small interfering ABCE1-targeting RNA inhibits the proliferation and invasiveness of small cell lung cancer. Int J Mol Med 25: 687-693, 2010.

17. Zheng HC, Xu XY, Xing YN, Wei ZL, Takahashi H, Masuda S and Takano Y: Nuclear or cytoplasmic localization of Bag-1 distinctly correlates with pathologic behavior and outcome of gastric carcinomas. Hum Pathol 41: 724-736, 2010.

18. Hassumi-Fukasawa MK, Miranda-Camargo FA, Zanetti BR, Galano DF, Ribeiro-Silva A and Soares EG: Expression of BAG-1 and PARP-1 in precursor lesions and invasive cervical cancer associated with human papillomavirus (HPV). Pathol Oncol Res 18: 929-937, 2012.

19. Noguchi T, Takeno S, Shibata T, Fumoto S, Uchida Y, Yokoyama S, Gabbert HE and Müller W: Nuclear BAG-1 expression is a biomarker of poor prognosis in esophageal squamous cell carcinoma. Dis Esophagus 16: 107-111, 2003.

20. Xia L, Guan W, Wang D, Zhang YS, Zeng LL, Li ZP, Wang G and Yang ZZ: Killing effect of Ad5/F35-APE1 siRNA recombinant adenovirus in combination with hematoporphrphyrin derivative-mediated photodynamic therapy on human nonsmall cell lung cancer. Biomed Res Int 2013: 957913, 2013.

21. Yi X, Zhao G, Zhang H, Guan D, Meng R, Zhang Y, Yang Q, Jia H, Dou K, Liu C, Que F and Yin JQ: MITF-siRNA formulation is a safe and effective therapy for human melasma. Mol Ther 19: 362-371, 2011.

22. Liu H, Liang Y, Li Y, Li YW, Wang J, Wu H, Wang Y, Tang SC, Chen J and Zhou Q: Gene silencing of BAG-1 modulates apoptotic genes and sensitizes lung cancer cell lines to cisplatin-induced apoptosis. Cancer Biol Ther 9: 832-840, 2010.

23. Wang T, Mi Y, Pian L, Gao P, Xu H, Zheng Y and Xuan X: RNAi targeting CXCR4 inhibits proliferation and invasion of esophageal carcinoma cells. Diagn Pathol 8: 104, 2013.

24. Shen YG, Xu YJ, Shi ZL, Han HL, Sun DQ and Zhang X: Effects of RNAi-mediated matrix metalloproteinase-2 gene silencing on the invasiveness and adhesion of esophageal carcinoma cells, KYSE150. Dig Dis Sci 57: 32-37, 2012.

25. Zhang S, Ding F, Luo A, Chen A, Yu Z, Ren S, Liu Z and Zhang L: XIAP is highly expressed in esophageal cancer and its downregulation by RNAi sensitizes esophageal carcinoma cell lines to chemotherapeutics. Cancer Biol Ther 6: 973-980, 2007.

26. Huang B, Gong X, Zhou H, Xiong F and Wang S: Depleting ABCE1 expression induces apoptosis and inhibits the ability of proliferation and migration of human esophageal carcinoma cells. Int J Clin Exp Pathol 7: 584-592, 2014. 